Perceptual \& Motor Skills: Motor Skills \& Ergonomics

2013, 117, 2,457-469. (C) Perceptual \& Motor Skills 2013

\title{
TENNIS PLAYING IS RELATED TO PSYCHOMOTOR SPEED IN OLDER DRIVERS ${ }^{1}$
}

\author{
JOSÉ MARMELEIRA \\ Department of Sport and Health, University of Évora, Portugal \\ Research Center in Sports Sciences \\ Health Sciences and Human Development (CIDESD), Portugal \\ FILIPE MELO \\ CIPER, Biolad, Faculty of Human Kinetics \\ University of Lisbon, Cruz Quebrada - Dafundo, Portugal \\ MOUHAYDINE TLEMCANI \\ Geophysics Center, University of Évora, Portugal \\ JORGE FERNANDES \\ Department of Sport and Health, University of Évora, Portugal
}

\begin{abstract}
Summary.-The study investigated the association of tennis playing and running with the psychomotor speed of older drivers. Thirty-six active male drivers ( $M$ age $=63.2 \mathrm{yr}$.) participated. A battery of four on-the road driving tests was performed by tennis players, runners, and a control group. Measures of simple and choice reaction time, movement time, and response time were collected under singleand dual-task conditions. A composite driving score was calculated from reaction time measures of all driving tasks to reflect a general drivers' psychomotor speed. Statistically significant differences between groups were found in a braking task; tennis players performed significantly better than controls in simple reaction time and response time. The composite driving score also differed between groups, and tennis players had better results than controls. Regular participation in tennis was related to psychomotor speed of older drivers.
\end{abstract}

Driving is a complex and interactive task that involves a variety of skills and requires the ability to make appropriate and timely decisions. For example, the speed at which visual information is processed is important to quick and appropriate responses in difficult or dangerous traffic situations (Anstey, Wood, Lord, \& Walker, 2005). It is known that biologic aging has a negative effect on reaction time (RT) in highly complex tasks (Der \& Deary, 2006). These detrimental effects may affect older adults'

\footnotetext{
${ }^{1}$ Address correspondence to José Marmeleira, Pavilhão Gimnodesportivo da Universidade de Évora, Prolongamento da Rua de Reguengos de Monsaraz, 14, 7000-727 Évora, Portugal or e-mail (jmarmel@uevora.pt).
} 